Article

\title{
Navigated 3D Ultrasound in Brain Metastasis Surgery: Analyzing the Differences in Object Appearances in Ultrasound and Magnetic Resonance Imaging
}

\author{
Benjamin Saß ${ }^{1, *(\mathbb{D})}$, Barbara Carl ${ }^{1,2}$, Mirza Pojskic ${ }^{1}$, Christopher Nimsky $^{1,3}{ }^{\mathbb{D}}$ and \\ Miriam Bopp 1,3 \\ 1 Department of Neurosurgery, University of Marburg, 35033 Marburg, Germany; \\ Barbara.Carl@helios-gesundheit.de (B.C.); Mirza.Pojskic@uk-gm.de (M.P.); \\ nimsky@med.uni-marburg.de (C.N.); bauermi@med.uni-marburg.de (M.B.) \\ 2 Department of Neurosurgery, Helios Dr. Horst Schmidt Kliniken, 65199 Wiesbaden, Germany \\ 3 Center for Mind, Brain and Behavior (CMBB), 35033 Marburg, Germany \\ * Correspondence: sassb@med.uni-marburg.de
}

Received: 4 October 2020; Accepted: 2 November 2020; Published: 3 November 2020

\begin{abstract}
Background: Implementation of intraoperative 3D ultrasound (i3D US) into modern neuronavigational systems offers the possibility of live imaging and subsequent imaging updates. However, different modalities, image acquisition strategies, and timing of imaging influence object appearances. We analyzed the differences in object appearances in ultrasound (US) and magnetic resonance imaging (MRI) in 35 cases of brain metastasis, which were operated in a multimodal navigational setup after intraoperative computed tomography based (iCT) registration. Method: Registration accuracy was determined using the target registration error (TRE). Lesions segmented in preoperative magnetic resonance imaging (preMRI) and i3D US were compared focusing on object size, location, and similarity. Results: The mean and standard deviation (SD) of the TRE was $0.84 \pm 0.36 \mathrm{~mm}$. Objects were similar in size (mean \pm SD in preMRI: $13.6 \pm 16.0 \mathrm{~cm}^{3}$ vs. i3D US: $13.5 \pm 16.0 \mathrm{~cm}^{3}$ ). The Dice coefficient was $0.68 \pm 0.22$ (mean $\pm \mathrm{SD}$ ), the Hausdorff distance $8.1 \pm 2.9 \mathrm{~mm}$ (mean \pm SD), and the Euclidean distance of the centers of gravity $3.7 \pm 2.5 \mathrm{~mm}$ (mean $\pm \mathrm{SD}$ ). Conclusion: i3D US clearly delineates tumor boundaries and allows live updating of imaging for compensation of brain shift, which can already be identified to a significant amount before dural opening.
\end{abstract}

Keywords: intraoperative ultrasound; intraoperative imaging; intraoperative computed tomography; brain metastasis; brain shift; brain distortion; neuronavigation

\section{Introduction}

Metastases are the most common brain tumors [1], with an estimated incidence being 3- to 10-fold higher than in primary brain tumors [2]. Despite tremendous advances in therapy, such as chemotherapy, immunotherapy, and targeted therapies [3], surgery and radiotherapy remain important cornerstones of the therapy [3-5]. Furthermore, the European Association of Neuro-Oncology recommends surgical resection in patients with a maximum of three metastases, especially when reaching a diameter of $3 \mathrm{~cm}$ or more, in cases of necrotic or cystic lesions, a distinct edema or mass effect, or an imminent danger of hydrocephalus as in posterior fossa lesions [5]. The development of image-guided surgery within the last decades including intraoperative magnetic resonance imaging (iMRI), computed tomography (iCT), and ultrasound (iUS) allows gross total resection with lower morbidity [6]. A well-described limitation of image-guided neurosurgery is brain shift [7], which is, among others, due to influences of gravity, brain swelling, loss of cerebrospinal fluid, tissue removal during surgery, and brain retraction [8,9]. First attempts to address this issue reach as far back as 1986, 
when Kelly et al. assessed brain movement during neurosurgical procedures. They placed stainless steel reference balls into the tumor and obtained radiographic images, which allowed computer adjustment for tumor location in three-dimensional space [10]. Subsequently, different methods to assess the extent of brain distortion were developed utilizing a navigated pointer [11,12], microscope [9], optical scanning [13], or analysis of video images [9]. IMRI [14,15] and iUS allow analyzation of brain shift and deformation of brain or tumor structures [8]. However, brain shift is a dynamic phenomenon occurring during the whole course of tumor resection, which can only be partially compensated by serially updated imaging [16]. While iMRI provides high-quality images, it is not widely available and has its drawbacks, such as an interruption of the surgical procedure, limitations in patient positioning, specific requirements on the organization of the operating theatre and staff [17], and, not least, high costs [18]. IUS, on the other hand, as introduced by Chandler et al. in 1982, who described the use of intraoperative brightness modulation (B-mode) ultrasound in 21 neurosurgical procedures [19] and began to use it routinely in their institution [20], provides real-time imaging without or at least with only minimal interruption of surgery, is nowadays widely available, and cost effective [21]. Initially, US did not receive much attention amongst neurosurgeons, probably mostly due to low imaging quality compared to other modalities, a lack of training and only few available specialized devices. The development of new integrative setups, combining neuronavigation and high quality ultrasound drew attention to this intraoperative imaging modality again [22,23]. A major step forward in the practical application of these systems was the introduction of navigated intraoperative 3D ultrasound (i3D US) [24,25], which allows updating of the 3D imaging data at several time points during surgery and delivers information on brain shift and resection extent with high specificity $[24,26]$.

A prerequisite for brain shift determination is an accurate registration of the preoperative imaging (e.g., MRI) and iUS. Using a navigational system, both modalities can be co-registered, reaching an average accuracy of less than $2 \mathrm{~mm}$ for deeply located reference structures, which are less prone to shifting, as demonstrated by Keles et al. [27]. Co-registration is based on the assumption of a rigid connection between the coordinate frames of the equipment (e.g., US probe) and the object of interest (patient's head). The violation of this basic assumption, caused by distortion within the brain tissue during surgery, results in a mismatch between preoperative and intraoperatively acquired imaging, which can be reported as brain shift [28,29], and is expected to a larger extent after durotomy [23].

Generally, iUS is believed to improve resection control in tumor surgery. However, Chacko et al. described a rate of $18 \%$ of discordance between $2 \mathrm{D}$ iUS and postoperative imaging with regards to the extent of tumor resection of parenchymal brain lesions [30]. Additionally, 2D ultrasound (either $5 \mathrm{MHz}$ phase array for deeply located or $10 \mathrm{MHz}$ for superficial lesions) was found to be less reliable than 1.5T iMRI in detecting small remnants of a size of less than $1 \mathrm{~cm}^{3}$ [31] and imaging quality diminishes during tumor resection [32]. Similarly, when using navigated 3D ultrasound in glioma surgery, Rygh et al. found a high specificity and sensitivity of $95 \%$ before resection, which decreased over the course of the operation and sensitivity was as low as $26 \%$ after resection, while specificity remained at $88 \%$ [33]. Nonetheless, the authors of the mentioned studies pointed out, that the benefits of iUS outbalance the shortcomings, provided the surgeon is aware of its limitations [30-33].

In our institution, navigated 3D ultrasound became fully implemented into the workflow of most cranial procedures. For tumor resection, navigated i3D US images are acquired routinely after craniotomy and as a resection control after tumor removal. Since the initial ultrasound acquisition is conducted before dural opening, one would assume the influence of brain shift to be moderate. However, displaying the ultrasound images as an overlay to the preoperative MRI during surgery conveys in some cases the impression of object incongruency, although this method only allows a gross estimation. Different aspects contributed to the decision to acquire the first i3D US before dural opening. First, the dural layer protects the brain and allows a gentle probe swiping over the surface without direct contact to the cortex, while it does not cause significant artifacts. Second, the tough dural layer also reduces the influence of probe pressure and brain pulsation. Finally, we aimed to address the question of how the imaging modalities MRI and iUS resemble each other, respectively, 
differ under optimal conditions of a minimized brain shift, which is given at the earliest possible operative stage right after craniotomy. To specify this, we prospectively obtained navigated i3D US datasets in a series of 35 cases of brain metastasis, which shared the feature to have more delineated boundaries in US than, e.g., gliomas, as described by Unsgaard et al. before [34]. We compared i3D US to preoperative MRI, analyzing the tumor volume, shape, and distance of segmented objects.

\section{Materials and Methods}

The prospective study included initially 37 patients, who were operated between February 2019 and July 2020. In the course of the study, two cases had to be excluded due incomplete image acquisition.

In all participants, preoperative MRI detected at least one lesion suggestive of brain metastasis and an interdisciplinary tumor board recommended resection. We obtained informed consent from all patients included in this study and received ethics approval for prospectively archiving clinical and technical data applying intraoperative imaging and navigation (study no. 99/18).

All patients received an MRI within a few days before resection, typically encompassing a 3D data set of T1-weighted contrast-enhanced images. These were transferred to the navigational system (Brainlab, Munich, Germany), which consists of a ceiling mounted double monitor (Curve, Brainlab, Munich, Germany) and two displays (Buzz, Brainlab, Munich, Germany) and navigational software.

All patients were operated under general anesthesia. After narcosis induction the patients were positioned on the operating room (OR) table and the head was fixed to a radiolucent carbon Doro head clamp with metallic pins. A reference array with four reflective markers was attached to the head clamp. Three fiducial markers were placed on the head within the scanning area, which were not needed for registration. The OR table was rotated $90^{\circ}$ to the 32-slice mobile CT scanner (AIRO, Brainlab, Munich) and a low-dose registration scan of $62 \mathrm{~mm}$ scan length was performed. Reflective markers, which are permanently attached to the AIRO scanner, and the reference array must be in the field of view of the navigational camera during the scanning process. The CT scan was automatically transferred to the navigational system and fused with the preoperative imaging datasets, establishing automatic patient registration. The patient was rotated back, and registration accuracy was checked by placing the navigational pointer into the divot of each skin fiducial. This allows the calculation of a target registration error as the Euclidian offset of the pointer tip. The reference array was removed and replaced by a sterile one after draping. Details of the aforementioned set-up, scanning process, and patient registration were published before [35].

All patients received $40 \mathrm{mg}$ of dexamethasone. After team time-out, skin disinfection, and sterile draping, the skin was incised. One-hundred-and-twenty-five milliliters of mannitol $15 \%$ was administered before craniotomy. After bone flap removal, and before dural opening, a navigated i3D US dataset was acquired using the bk5000 system (bk medical, Herlev, Denmark), which was connected to the navigational system. For acquisition, a reference array with three reflective markers is attached to the precalibrated bk medical transducer N13C5, which is fully immersible, can be sterilized and therefore be used without a sterile cover. The transducer offers a convex contact surface of $29 \times 10 \mathrm{~mm}$ and has a scanning frequency of 5-13 MHz. Whenever possible, the patient's head was positioned in a way exposing the dura horizontally after bone removal, allowing a saline depot to be administered as a coupling fluid. During image acquisition the probe was smoothly swept over the dura, whilst the reference arrays attached to the head clamp and the transducer were in the line of sight of the navigational camera (Figure A1). The bk5000 actually generated 2D slices of $0.3 \mathrm{~mm}$, which were transformed into 3D image volumes and automatically registered by the navigational software (Figure 1a). Those 3D data sets, which were now available during the further surgical procedure, were displayed in an overlay or side-by-side fashion, or as a standalone and could be reformatted to an oblique plane matching the surgeon's view through the operating microscope (Figure $1 b, c)$. A second image acquisition was performed after tumor removal as a resection control or if demanded at any timepoint during the surgery. 


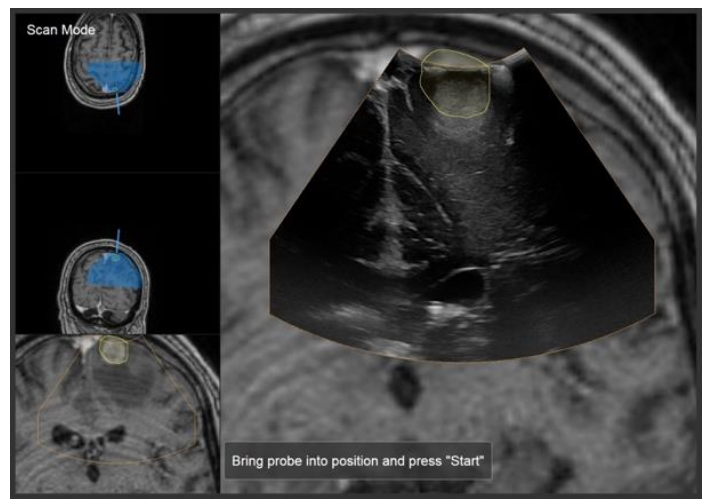

(a)

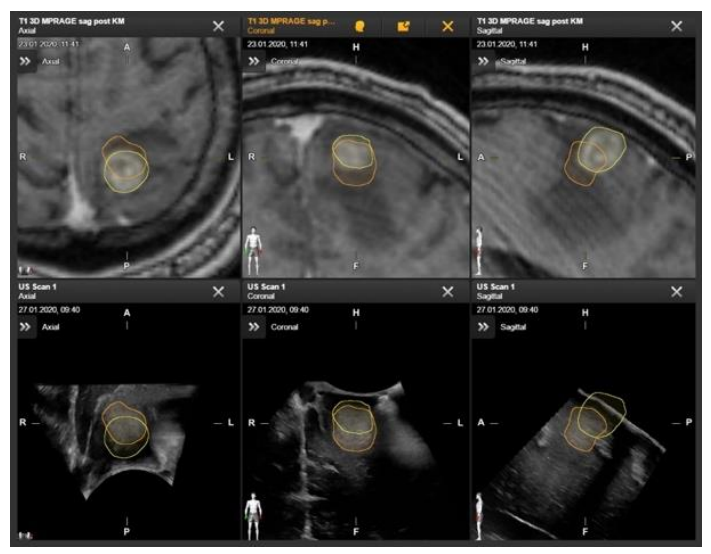

(b)

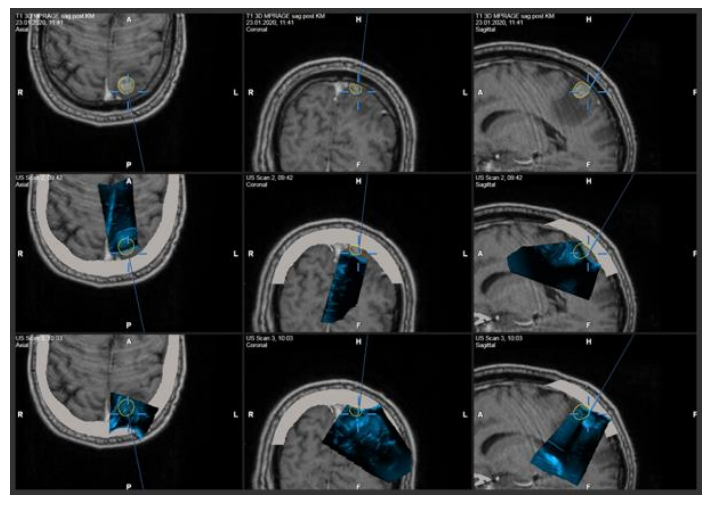

(c)

Figure 1. (a) Live view of precalibrated ultrasound just before image acquisition. The yellow lines indicate the tumor boundaries segmented in preMRI, depicting a spatial deviation. (b) Simultaneous visualization of preMRI and corresponding i3D US slices. Segmented tumor objects are displayed in yellow (preMRI) and orange (i3D US). (c) During surgery preMRI and i3D US datasets were acquired during different surgical steps (1st row preMRI, 2nd row before dural opening, and 3rd row after tumor resection) are displayed in an overlay fashion. Yellow lines indicate the preMRI tumor segmentation.

Lesions were identified and segmented in the preMRI and pre-resectional ultrasound using the smart brush tool element (Brainlab, Munich, Germany) in the navigational software, which automatically calculates the tumor volume. The 3D datasets were exported to MeVisLab (MeVis Medical Solutions AG, Bremen, Germany) for further calculations. To assess similarity of the objects, the Dice coefficient [36] and the Hausdorff distances were computed. 
The Dice coefficient $\left(C_{D S C}\right)$ is a spatial overlap index that can be used for comparing segmented objects $[37,38]$ and is calculated as

$$
C_{D s c}=\frac{2\left|A_{U S} \cap B_{M R}\right|}{\left|A_{U S}\right|+\left|B_{M R}\right|}
$$

where $A_{U S}$ and $B_{M R}$ are number of voxels of the segmented objects. The Dice coefficient is restricted to values between 0 and 1 , with a value of 0 indicating no overlap and a value of 1 representing an exact match [38].

The Hausdorff distance measures the extent to which each voxel of one segmentation lies near to some voxel of the other segmentation, and vice versa [39]. The calculated distance can be used to measure the degree of resemblance of the object contours [38,39].

The formula is defined as

$$
H\left(A_{U S}, B_{M R}\right)=\max \left\{d_{\max }\left(A_{U S}, B_{M R}\right), d_{\max }\left(B_{M R}, A_{U S}\right)\right\}
$$

with $d_{\max }=\max _{a \in A_{\text {US }}} \min _{b \in B_{M R}}\|a-b\|[38,39]$.

The Hausdorff distance is measured in $\mathrm{mm}$; it is a small distance indicating a good resemblance of the segmented objects [38].

Furthermore, the geometric centers of gravity $(\mathrm{CoG})$ were calculated, which have the advantage of being invariant under rotation, scaling and skewing, and a stable measurement even under random noise [40]. The CoG has been used for measuring the displacement of objects in different MRI sequences before [41]. Put simply, the geometric center of gravity is calculated by summing up the coordinates of voxels, divided by the number of voxels:

$$
C o G_{U S}=\frac{1}{\left|A_{U S}\right|} \times \sum_{a \in A_{U S}} a \text { and } C_{0} G_{M R}=\frac{1}{\left|B_{M R}\right|} \times \sum_{b \in B_{M R}} b
$$

The displacement is calculated by subtraction of the geometric centers of gravity, expressed as Euclidean distance.

For statistical analysis GrapPad Prism 8.4.3 (GrapPad Software, San Diego, CA, USA) for MacOS was used.

If necessary, testing for normal distribution was performed using the D'Agostino and Pearson test. For the analysis of not normally distributed data either the two-tailed Mann-Whitney test (un-paired) or the Wilcoxon matched-pairs signed rank test (paired data) were used.

A $p$-value $<0.05$ was considered statistically significant.

\section{Results}

\subsection{Patient Characteristics}

Of the 37 patients, two had to be excluded because the acquired i3D US did not capture the whole lesion due to artifacts. Of the remaining 35, 18 were females and 17 males. Mean patient age was $62.7 \pm 12.1$ (mean $\pm \mathrm{SD}$ ) years, ranging from 28.6 to 79.1 years. Thirty-one patients suffered from single brain metastasis and four were diagnosed with more than one lesion. The most common tumor location was in the frontal lobe (15), followed by the parietal (five, of which each one was temporo-parietal or parieto-occipital), occipital (five), and temporal (two). In six cases, the tumor was located cerebellar. One lesion was located at the head of the caudate nucleus, and one lesion was insular. Histopathological work-up revealed metastasis of an adenocarcinoma of the lung in eleven cases and neuroendocrine carcinoma of the lung in three cases. In seven patients, a melanoma was found as the primary site, three patients suffered from breast cancer, four were diagnosed with renal cell carcinoma, six with gastrointestinal adenocarcinoma encompassing colon (three), gall bladder (one), esophagus (one), and one which was not specified further. One lesion was defined as a carcinoma of unknown primary site. Table 1 summarizes patient characteristics. 
Table 1. Patient characteristics.

\begin{tabular}{|c|c|c|c|c|}
\hline Case & $\begin{array}{c}\text { Age } \\
\text { [Years] }\end{array}$ & Sex & Localization & $\begin{array}{c}\text { Diagnosis/ } \\
\text { Primary Tumor }\end{array}$ \\
\hline 1 & 59.5 & male & left frontal & melanoma \\
\hline 2 & 73.3 & male & right frontal & ADC, colon \\
\hline 3 & 32.7 & male & left frontal & melanoma \\
\hline 4 & 64.2 & male & cerebellar & ADC, lung \\
\hline 5 & 50.7 & female & left temporal & ADC, lung \\
\hline 6 & 69.0 & male & right parieto-occipital & ADC, gall bladder \\
\hline 7 & 78.1 & male & cerebellar & RCC \\
\hline 8 & 76.6 & female & left occipital & ADC, lung \\
\hline 9 & 79.1 & male & right frontal & RCC \\
\hline 10 & 62.8 & female & left frontal & ADC, lung \\
\hline 11 & 57.2 & female & left frontal & CA, CUP \\
\hline 12 & 59.2 & female & cerebellar & ADC, lung \\
\hline 13 & 62.8 & female & left frontal & NEC, lung \\
\hline 14 & 56.7 & female & left frontal & melanoma \\
\hline 15 & 67.3 & female & left parietal & RCC \\
\hline 16 & 72.8 & male & right insular & ADC, GI \\
\hline 17 & 74.1 & female & left occipital & ADC, colon \\
\hline 18 & 71.1 & male & cerebellar & $\mathrm{RCC}$ \\
\hline 19 & 56.0 & male & left frontal & melanoma \\
\hline 20 & 28.6 & female & right frontal & mammary CA (NST) \\
\hline $21 *$ & 53.5 & male & right frontal & NEC, lung \\
\hline 22 & 50.5 & female & right occipital & melanoma \\
\hline 23 & 59.5 & male & left parietal & ADC, lung \\
\hline 24 & 51.2 & female & cerebellar & NEC, lung \\
\hline 25 & 65.3 & female & left temporo-parietal & ADC, lung \\
\hline 26 & 74.6 & female & left occipital & ADC, colon \\
\hline 27 & 71.5 & male & left frontal & ADC, esophagus \\
\hline 28 & 78.2 & male & left temporal & melanoma \\
\hline 29 & 67.6 & female & left parietal & NEC, lung \\
\hline 30 & 69.5 & female & cerebellar & $\mathrm{ADC}$, lung \\
\hline 31 & 55.4 & female & right frontal & ADC, lung \\
\hline 32 & 70.7 & male & right frontal & ADC, lung \\
\hline 33 & 41.8 & female & right frontal & mammary ADC \\
\hline 34 & 69.7 & male & right parietal & mammary ADC \\
\hline 35 & 58.6 & male & left CN & melanoma \\
\hline 36 & 58.6 & male & left frontal & ADC, lung \\
\hline $37 *$ & 64.9 & female & left frontal & ADC, lung \\
\hline
\end{tabular}

ADC: adenocarcinoma; CA: carcinoma; CN: caudate nucleus; CUP: carcinoma of unknown primary site; GI: gastrointestinal; NEC: neuroendocrine carcinoma; NST: no specific type; RCC: renal cell carcinoma; ${ }^{*}$ patient excluded.

\subsection{Tumor Object Characteristics}

Table 2 summarizes tumor object characteristics and reports the target registration error.

Descriptive analysis of the segmented tumor volumes revealed a mean tumor volume of $13.6 \pm 16.0 \mathrm{~cm}^{3}$ (mean $\pm \mathrm{SD}$ ) and a median of $8.5 \mathrm{~cm}^{3}$ in MRI, whereas it was $13.5 \pm 16.0 \mathrm{~cm}^{3}$ (mean $\left.\pm \mathrm{SD}\right)$ with a median of $8.8 \mathrm{~cm}^{3}$, when segmented in ultrasound. The data were not normally distributed (D'Agostino and Pearson test). For further analysis a two-tailed Wilcoxon matched pairs test was used (Figure 2), demonstrating a median of differences of $0.11 \mathrm{~cm}^{3}$, which was not significant $(p=0.0595)$. To take into account that some of the values were negative and thus the median of differences might be misleading, we also determined the median of the magnitude of the differences, which was $0.40 \mathrm{~cm}^{3}$. 
Table 2. Tumor object characteristics and the target registration error (TRE).

\begin{tabular}{|c|c|c|c|c|c|c|}
\hline Case & $\begin{array}{c}\text { Tumor Volume } \\
\text { MRI } \\
{\left[\mathrm{cm}^{3}\right]}\end{array}$ & $\begin{array}{c}\text { Tumor Volume } \\
\text { US } \\
{\left[\mathrm{cm}^{3}\right]}\end{array}$ & $\begin{array}{c}\text { Dice } \\
\text { Coefficient * }\end{array}$ & $\begin{array}{c}\text { Hausdorff } \\
\text { Distance } \\
{[\mathrm{mm}]}\end{array}$ & $\begin{array}{l}\text { Center of } \\
\text { Gravity }{ }^{* *} \\
{[\mathrm{~mm}]}\end{array}$ & $\begin{array}{c}\text { Target Registration } \\
\text { Error } \\
{[\mathrm{mm}]}\end{array}$ \\
\hline 2 & 5.84 & 5.34 & 0.68 & 7.33 & 4.56 & 0.45 \\
\hline 3 & 23.90 & 23.80 & 0.84 & 8.41 & 2.42 & 1.51 \\
\hline 4 & 1.19 & 1.14 & 0.73 & 4.50 & 1.95 & 1.21 \\
\hline 7 & 3.42 & 3.10 & 0.78 & 4.39 & 1.96 & 0.93 \\
\hline 8 & 6.95 & 7.90 & 0.85 & 4.29 & 1.30 & 0.78 \\
\hline 9 & 9.63 & 9.83 & 0.83 & 5.73 & 2.63 & 0.63 \\
\hline 10 & 0.43 & 0.47 & 0.21 & 6.00 & 4.84 & 0.93 \\
\hline 11 & 77.70 & 77.60 & 0.88 & 8.10 & 2.56 & 0.41 \\
\hline 16 & 34.40 & 32.40 & 0.87 & 6.29 & 2.58 & 0.92 \\
\hline 17 & 11.1 & 10 & 0.72 & 9.60 & 4.44 & 0.45 \\
\hline 18 & 28.10 & 26.30 & 0.86 & 6.02 & 1.94 & 0.72 \\
\hline 19 & 12.00 & 10.90 & 0.73 & 8.78 & 5.09 & 0.56 \\
\hline 20 & 6.24 & 5.59 & 0.46 & 9.12 & 5.44 & 0.41 \\
\hline 22 & 42.40 & 41.00 & 0.64 & 11.70 & 7.13 & 1.11 \\
\hline 23 & 1.71 & 1.38 & 0.38 & 8.60 & 6.52 & 0.68 \\
\hline 24 & 14.30 & 13.90 & 0.77 & 6.60 & 3.26 & 1.58 \\
\hline 25 & 19.90 & 20.20 & 0.85 & 6.77 & 0.72 & 1.16 \\
\hline 26 & 6.73 & 7.69 & 0.71 & 9.15 & 2.61 & 0.80 \\
\hline 27 & 4.62 & 3.62 & 0.74 & 7.59 & 3.18 & 1.13 \\
\hline 35 & 28.80 & 33.30 & 0.81 & 7.81 & 2.96 & 0.37 \\
\hline 36 & 0.71 & 1.00 & 0.32 & 8.53 & 5.47 & 0.76 \\
\hline
\end{tabular}

* without units; ${ }^{* *}$ Euclidean distance of the geometric centers of gravity.

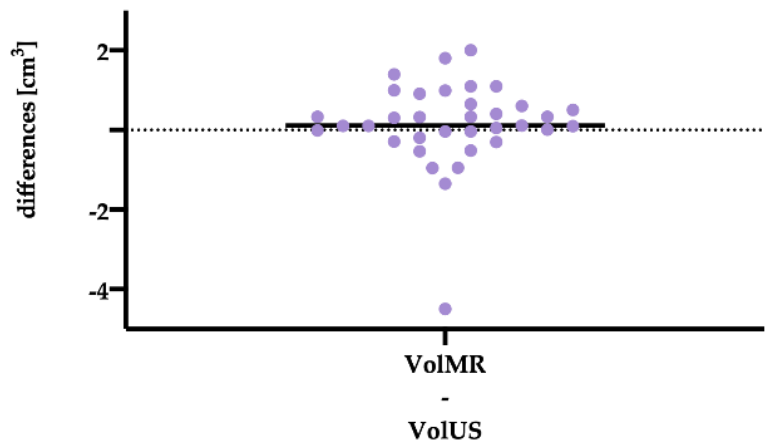

Figure 2. Scatter plot of the differences of volumes in MRI (VolMR) and US (VolUS). The line indicates the median difference.

The mean Dice coefficient $C_{\text {DSC }}$ was $0.68 \pm 0.22$ (mean \pm SD) with a median of 0.75 . As demonstrated in Figure 3, the Dice coefficient ranged from 0 (case no. 31) to 0.88 (case no. 11).

When looking at the cases with a Dice coefficient below 0.5 , it is noteworthy that the median tumor size (segmented in MRI) was significantly ( $p=0.0001$, two-tailed Mann-Whitney test) smaller in this subgroup $\left(0.7 \mathrm{~cm}^{3}\right.$ vs. $\left.9.8 \mathrm{~cm}^{3}\right)$. MRI-segmented tumor volume and Dice coefficient correlated positively ( $r=0.59, p=0.0002$, nonparametric Spearman correlation). The same applied when the Dice 
coefficient was correlated to the volume of the segmented US objects $(\mathrm{r}=0.58, p=0.0003$, nonparametric Spearman correlation).

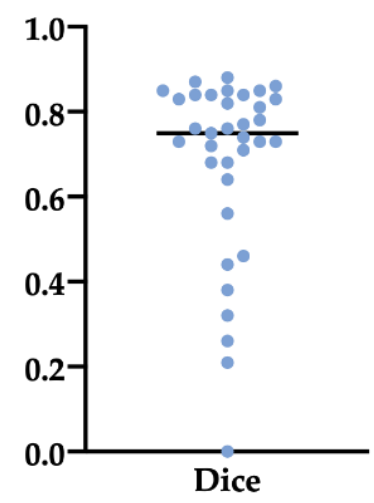

Figure 3. Scatter plot of the Dice coefficients. The line represents the median Dice coefficient of 0.75.

The Hausdorff distance was $8.1 \pm 2.9 \mathrm{~mm}$ (mean $\pm \mathrm{SD}$ ), respectively, $8.1 \mathrm{~mm}$ (median), whereas the Euclidean distance of the geometric centers of gravity was $3.7 \pm 2.5 \mathrm{~mm}$ (mean $\pm \mathrm{SD}$ ) with a median of $3.0 \mathrm{~mm}$, see Figure 4.

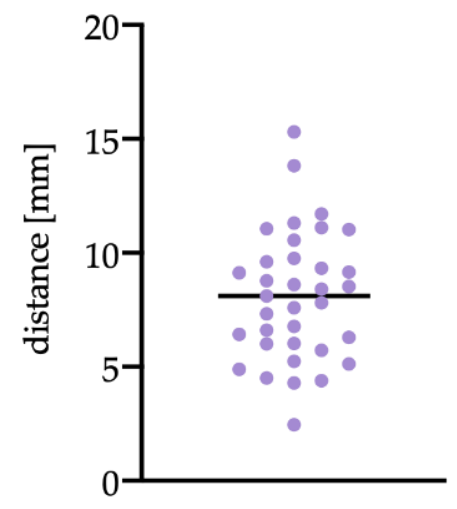

(a)

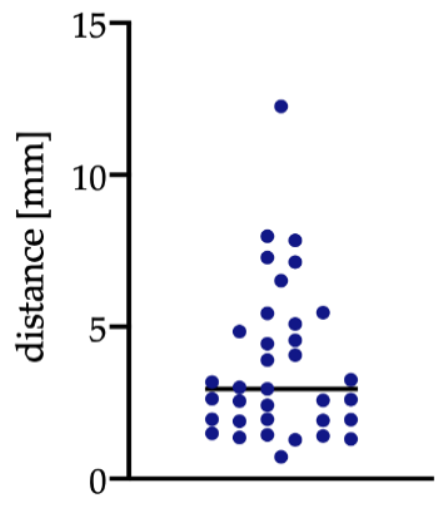

(b)

Figure 4. Scatterplots with median line of (a) Hausdorff distance. Median: $8.1 \mathrm{~mm}$, mean \pm SD: $8.1 \pm 2.9 \mathrm{~mm}$. (b) Euclidean distance of geometric center of gravity. Median: $3.0 \mathrm{~mm}$, mean \pm SD: $3.7 \pm 2.5 \mathrm{~mm}$.

\subsection{Influence of Registration}

The mean TRE was $0.84 \pm 0.36 \mathrm{~mm}$ (mean \pm SD) with a median of $0.79 \mathrm{~mm}$, in three cases the TRE could not be quantified. The TRE did neither correlate with the Dice coefficient $(r=0.14, p=0.4369$, Spearman correlation) nor the Hausdorff distance ( $\mathrm{r}=-0.04, p=0.8242$, Spearman correlation). TRE and the Euclidean distance of the geometric center of gravity correlated negatively $(r=-0.3616$, $p=0.0420$, Spearman correlation), demonstration only a week association of the registration accuracy and brain shift.

\section{Discussion}

Despite an enormous increase in ultrasound image quality in recent years, recognizing anatomical structures in oblique and narrow US sections can become tedious. The first attempts to address this issue date as far back as 1993, when Koivukangas et al. used intraoperative ultrasound as a control 
for reformatted CT and MRI image sets during neurosurgical procedures by establishing a common axes on which preoperative and intraoperative images where aligned [42]. However, only when trackable US probes were developed, US and navigational systems were able to coalesce to integrated systems $[22,43,44]$, which allowed displaying preoperative and intraoperative image sets as overlays or side-by-side $[23,28]$.

This baseline study was conducted to describe the obvious differences in object appearances in iUS and preoperative MRI at the earliest possible surgical stage after craniotomy. We chose to acquire the iUS-scan before dural opening, to keep the influence of brain shifting as low as possible and to enable a comparison of the imaging modalities under optimized conditions.

Initial patient registration was achieved by an iCT scan and fusion to the preoperative MRI data sets with high accuracy (mean \pm SD TRE: $0.84 \pm 0.36 \mathrm{~mm}$ ), which is comparable to our previously published data [35]. The US probes were precalibrated, meaning that they were fully implemented into the navigational system, and thus a co-registration was automatically established. This kind of MRI and US fusion is based on spatial position information and can be categorized as a rigid or non-deformable registration $[45,46]$. Alternatively, rigid registration can be performed image-based using different algorithms to match structures in MRI and US [47,48], but any non-deformable registration approach does not tackle the issue of brain deformation and distortion. However, rigid co-registration allowed the assessment of the spatial deviation and deformation of structures segmented in both modalities. Statistical analysis of the segmented tumor volumes in preoperative MRI and intraoperative US revealed a very similar mean \pm SD (preMRI: $13.6 \pm 16.0 \mathrm{~cm}^{3}$; iUS: $13.5 \pm 16.0 \mathrm{~cm}^{3}$ ) and median (preMRI: $8.5 \mathrm{~cm}^{3}$; iUS: $8.8 \mathrm{~cm}^{3}$ ), which did not differ significantly. The median of the magnitude of the differences was $0.40 \mathrm{~cm}^{3}$. These results indicate both modalities being comparable with respect to tumor delineation. This might be partially fostered by the study design that only included brain metastases, whose tumor boundaries could be clearly identified in both T1-enhanced MRI and US. Including gliomas in this study, especially low-grade gliomas, on the other hand, would have made tumor identification and subsequent analysis of data dependent on the segmentation much more difficult.

Spatial overlap was assessed using the Dice coefficient, which was $0.68 \pm 0.22$ (mean \pm SD) with a median of 0.75 , where 1.0 would indicate a perfect match and 0 no association at all [36]. Consistently, the Dice coefficient correlated positively to the tumor size. Even though the Dice coefficient is thought to allow straightforward comparison, interpretation of the coefficient in this study must take into account several factors. First, the calculated measures are influenced by segmentation inaccuracy, as shown by Zou et al., who found in a series of repeated segmentation of the prostate peripheral zone in patients with prostate cancer, a mean Dice coefficient of 0.883 in $1.5 \mathrm{~T}$ MRI and 0.838 in $0.5 \mathrm{~T}$ MRI segmentations [37]. Interestingly, the same work group compared manual segmentations of brain tumors to a semi-automated probabilistic fractional segmentation and found wide ranges of the Dice coefficients (0.487-0.972) [37]. Additionally, Nitsch et al. compared automatic segmentations of the falx and tentorium to manual segmentations of an expert in US and found an average Dice coefficient of 0.74 . They also found a very high inter-observer variability in segmentations resulting in a Dice coefficient of $0.52-0.83$ [38]. Secondly, spatial overlap is influenced by brain shift. With respect to this, we determined the Euclidean distance of the geometric centers of gravity, which were $3.7 \pm 2.5 \mathrm{~mm}$ (mean $\pm \mathrm{SD}$ ) with a median of $3.0 \mathrm{~mm}$, indicating a relevant shift of the segmented objects. Although the main shifting takes place after dural opening, Hill et al. reported a dural displacement of $1.2 \mathrm{~mm}$ right after craniotomy [12]. However, Ohue et al. found a brain shift of $3.4 \pm 1.9 \mathrm{~mm}$ (range: $0.4-10.8 \mathrm{~mm}$ ) at the tumor margins before dural opening, which was increased to $5.1 \pm 2.7 \mathrm{~mm}$ (range: $0.9-15.7 \mathrm{~mm}$ ) before tumor removal [23] and Letteboer et al. reported an average brain shift of $3.0 \mathrm{~mm}$ parallel to the direction of gravity and $3.9 \mathrm{~mm}$ perpendicular to the direction of gravity before dural opening. They described only an additional shift of $0.2 \mathrm{~mm}$ to the direction of gravity respectively $1.4 \mathrm{~mm}$ in the perpendicular plane after durotomy [29]. Sastry et al. discussed this unexpected finding of a larger extent of brain shift before dural opening to be attributed to calibration errors rather than true brain shift [21]. Although our study incorporated the evaluation of the registration procedure, 
the quality of the co-registration of the precalibrated US probes was not determined for each single case. To overcome this issue, we performed an accuracy measurement using a tracked ultrasound phantom containing wires. The expected positions of the wires were displayed within the US image and the offset was calculated to be $1.33 \pm 0.33 \mathrm{~mm}$ (mean $\pm \mathrm{SD}$ ).

To evaluate object deformation possibly caused by either brain shift or the pressure applied with the US probe on the tissue during i3D US image acquisition, we analyzed the resemblance of segmented tumor objects in preMRI and iUS by calculating the Hausdorff distance [38,39], resulting in a mean of $8.1 \mathrm{~mm}$ (SD: $\pm 2.9 \mathrm{~mm}$ ) and a median of $8.1 \mathrm{~mm}$. Interestingly, our computed value was lower than in the above citied study of Nitsch et al., who compared automatic and manual segmentations of rigid and deeply located anatomic structures in one and the same US and found a Hausdorff distance of $12.2 \mathrm{~mm}$ [38]. Thus, segmentations were similar in preMRI and iUS and the deformation of the US objects was only moderate. We conclude that the brain shift is on the one hand partially due to the craniotomy and on the other hand influenced by the probe placement. However, unraveling the impact of each of these factors is virtually impossible, because first the iUS can only be performed after craniotomy and second the acquisition of ultrasound images requires contact to the brain's surface.

Finally, the influence of the initial registration procedure expressed as TRE on the Dice coefficient, the Hausdorff distance, and the Euclidean distance of the geometric centers of gravity was evaluated facilitated by correlation analysis. Solely TRE and Euclidean distance of the geometric centers of gravity showed a significant $(p=0.0420)$, but only moderate negative correlation $(r=-0.3616)$. Taken together, the influence of the initial registration procedure was low, which is not surprising, given the very low TRE.

Among the limitations of this study was the exclusion of two cases, in which the acquired i3D US datasets did not fully cover the lesions, and three cases, in which the TRE was not available. However, the amount of collected data is still large enough to allow a reliable evaluation. Another drawback is the fact that the quality of the precalibration, respectively, the co-registration of the US probes was not sufficiently assessed for each case. When reflecting the results of the accuracy measurement in a phantom, which showed an offset of $1.3 \mathrm{~mm}$, compared to the Euclidean distance of the geometric centers of gravity (mean $\pm \mathrm{SD}: 3.7 \pm 2.5 \mathrm{~mm}$ ) and the partially small tumor volumes, we see the need for further improvement in future applications. However, we believe the influence of the precalibration error to be within a just acceptable range.

Summing up the results of this study, we found the segmented tumor objects in i3D US clearly delineated the tumor boundaries and was comparable to preMRI segmentations. Dice coefficient and Euclidean distance of geometric centers of gravity indicated a moderate brain shift even before dural opening, and the Hausdorff distance of $8.1 \mathrm{~mm}$ suggested a good resemblance of the objects with only moderate deformation. Both the measured shift and deformation might be partially affected by the pressure applied with the US probe during image acquisition and calibration inaccuracy to some extent. An additional feature of i3D US, which was not evaluated in this study, is the possibility of updating the navigation during surgery based on i3D US. The simplest way to do so is to rely solely on the i3D US data sets rigid co-registration of preoperative and intraoperative imaging is limited by brain deformation or distortion. Approaches addressing this problem utilize deformable methods [49], different mathematical algorithms [7], and deep learning with convolutional neural networks to improve registration and segmentations [50]. Yet, all of these share the common feature of an increase in computation time and registration uncertainty [51], making them less suitable for routine use in brain tumor resection when compared to fully implemented rigidly co-registrated US.

Taken together, even under optimal conditions, we found differences in object appearances in both modalities. Nevertheless, we conclude that our study contributes to the body of literature showing that the rigid co-registration of i3D US utilizing a precalibrated trackable transducer offers a valuable supplement to multimodal neuronavigational set-ups with high imaging quality allowing a precise depiction of pathologies, whereby it is straightforward in use and allows convenient integration in preexisting systems and workflows. 
Author Contributions: Conceptualization, M.B., C.N., and B.S.; methodology, M.B. and B.S; validation, B.C., C.N., and M.P.; investigation, M.B. and B.S.; resources, M.B., B.C., C.N., M.P., and B.S.; data curation, M.B. and B.S.; writing-original draft preparation, B.S.; writing-review and editing, M.B. and C.N.; visualization, M.B. and B.S.; supervision, M.B., C.N., and B.S.; project administration, M.B. All authors have read and agreed to the published version of the manuscript.

Funding: This research received no external funding.

Conflicts of Interest: The authors declare no conflict of interest.

\section{Appendix A}

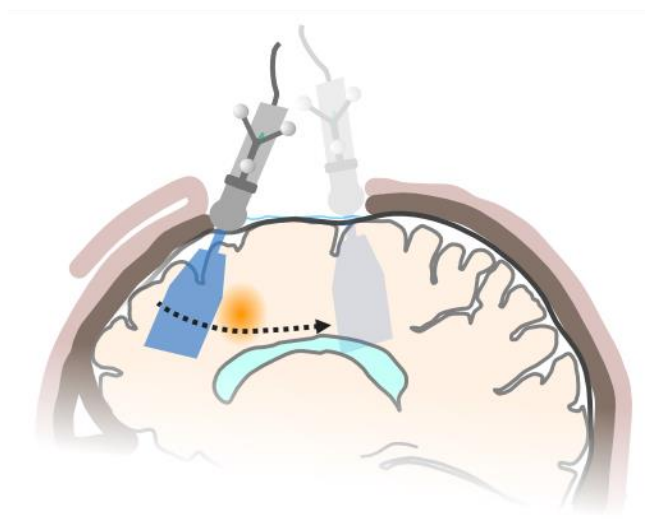

Figure A1. Acquisition of i3D US. The navigated US probe is swiped over the dural layer. The reference array on the probe and the head clamp must be in the sight of line of the navigational camera. 2D slices of $0.3 \mathrm{~mm}$ are generated and transformed to a 3D data set.

\section{References}

1. Tabouret, E.; Chinot, O.; Metellus, P.; Tallet, A.; Viens, P.; Goncalves, A. Recent trends in epidemiology of brain metastases: An overview. Anticancer Res. 2012, 32, 4655-4662. [PubMed]

2. Davis, F.G.; Dolecek, T.A.; McCarthy, B.J.; Villano, J.L. Toward determining the lifetime occurrence of metastatic brain tumors estimated from 2007 United States cancer incidence data. Neuro-Oncology 2012, 14, 1171-1177. [CrossRef] [PubMed]

3. Lauko, A.; Rauf, Y.; Ahluwalia, M.S. Medical management of brain metastases. Neuro-Oncol. Adv. 2020, 2, vdaa015. [CrossRef] [PubMed]

4. Sankey, E.W.; Tsvankin, V.; Grabowski, M.M.; Nayar, G.; Batich, K.A.; Risman, A.; Champion, C.D.; Salama, A.K.S.; Goodwin, C.R.; Fecci, P.E. Operative and peri-operative considerations in the management of brain metastasis. Cancer Med. 2019, 8, 6809-6831. [CrossRef] [PubMed]

5. Soffietti, R.; Abacioglu, U.; Baumert, B.; Combs, S.E.; Kinhult, S.; Kros, J.M.; Marosi, C.; Metellus, P.; Radbruch, A.; Villa Freixa, S.S.; et al. Diagnosis and treatment of brain metastases from solid tumors: Guidelines from the European Association of Neuro-Oncology (EANO). Neuro Oncol. 2017, 19, 162-174. [CrossRef] [PubMed]

6. Vogelbaum, M.A.; Suh, J.H. Resectable brain metastases. J. Clin. Oncol. 2006, 24, 1289-1294. [CrossRef]

7. Bayer, S.; Maier, A.; Ostermeier, M.; Fahrig, R. Intraoperative Imaging Modalities and Compensation for Brain Shift in Tumor Resection Surgery. Int. J. Biomed. Imaging 2017, 2017, 1-18. [CrossRef] [PubMed]

8. Nimsky, C.; Ganslandt, O.; Cerny, S.; Hastreiter, P.; Greiner, G.; Fahlbusch, R. Quantification of, visualization of, and compensation for brain shift using intraoperative magnetic resonance imaging. Neurosurgery 2000, 47, 1070-1079. [CrossRef]

9. Roberts, D.W.; Hartov, A.; Kennedy, F.E.; Miga, M.I.; Paulsen, K.D. Intraoperative brain shift and deformation: A quantitative analysis of cortical displacement in 28 cases. Neurosurgery 1998, 43, 749-758. [CrossRef] [PubMed]

10. Kelly, P.J.; Kall, B.A.; Goerss, S.; Earnest, F.T. Computer-assisted stereotaxic laser resection of intra-axial brain neoplasms. J. Neurosurg. 1986, 64, 427-439. [CrossRef] 
11. Dorward, N.L.; Alberti, O.; Velani, B.; Gerritsen, F.A.; Harkness, W.F.; Kitchen, N.D.; Thomas, D.G. Postimaging brain distortion: Magnitude, correlates, and impact on neuronavigation. J. Neurosurg. 1998, 88, 656-662. [CrossRef]

12. Hill, D.L.; Maurer, C.R., Jr.; Maciunas, R.J.; Barwise, J.A.; Fitzpatrick, J.M.; Wang, M.Y. Measurement of intraoperative brain surface deformation under a craniotomy. Neurosurgery 1998, 43, 514-526. [CrossRef]

13. Audette, M.A.; Siddiqi, K.; Peters, T.M. Level-Set Surface Segmentation and Fast Cortical Range Image Tracking for Computing Intrasurgical Deformations. In Medical Image Computing and Computer-Assisted Intervention-MICCAI'99, Proceeding of the International Conference on Medical Image Computing and Computer-Assisted Intervention, Cambridge, UK, 19-22 September, 1999; Springer: Berlin/Heidelberg, Germany, 1999; pp. 788-797.

14. Wirtz, C.R.; Bonsanto, M.M.; Knauth, M.; Tronnier, V.M.; Albert, F.K.; Staubert, A.; Kunze, S. Intraoperative magnetic resonance imaging to update interactive navigation in neurosurgery: Method and preliminary experience. Comput. Aided Surg. 1997, 2, 172-179. [CrossRef] [PubMed]

15. Nimsky, C.; Ganslandt, O.; Hastreiter, P.; Fahlbusch, R. Intraoperative compensation for brain shift. Surg. Neurol. 2001, 56, 357-364. [CrossRef]

16. Nabavi, A.; Black, P.M.; Gering, D.T.; Westin, C.F.; Mehta, V.; Pergolizzi, R.S., Jr.; Ferrant, M.; Warfield, S.K.; Hata, N.; Schwartz, R.B.; et al. Serial intraoperative magnetic resonance imaging of brain shift. Neurosurgery 2001, 48, 787-797. [CrossRef]

17. Nimsky, C.; Ganslandt, O.; von Keller, B.; Romstock, J.; Fahlbusch, R. Intraoperative high-field-strength MR imaging: Implementation and experience in 200 patients. Radiology 2004, 233, 67-78. [CrossRef]

18. Reinertsen, I.; Lindseth, F.; Askeland, C.; Iversen, D.H.; Unsgard, G. Intra-operative correction of brain-shift. Acta Neurochir. 2014, 156, 1301-1310. [CrossRef] [PubMed]

19. Chandler, W.F.; Knake, J.E.; McGillicuddy, J.E.; Lillehei, K.O.; Silver, T.M. Intraoperative use of real-time ultrasonography in neurosurgery. J. Neurosurg. 1982, 57, 157-163. [CrossRef] [PubMed]

20. Knake, J.E.; Chandler, W.F.; McGillicuddy, J.E.; Silver, T.M.; Gabrielsen, T.O. Intraoperative sonography for brain tumor localization and ventricular shunt placement. Am. J. Roentgenol. 1982, 139, 733-738. [CrossRef]

21. Sastry, R.; Bi, W.L.; Pieper, S.; Frisken, S.; Kapur, T.; Wells, W., III; Golby, A.J. Applications of Ultrasound in the Resection of Brain Tumors. J. Neuroimaging 2017, 27, 5-15. [CrossRef]

22. Gronningsaeter, A.; Kleven, A.; Ommedal, S.; Aarseth, T.E.; Lie, T.; Lindseth, F.; Lango, T.; Unsgard, G. SonoWand, an ultrasound-based neuronavigation system. Neurosurgery 2000, 47, 1373-1379. [CrossRef]

23. Ohue, S.; Kumon, Y.; Nagato, S.; Kohno, S.; Harada, H.; Nakagawa, K.; Kikuchi, K.; Miki, H.; Ohnishi, T. Evaluation of intraoperative brain shift using an ultrasound-linked navigation system for brain tumor surgery. Neurol. Med. Chir. 2010, 50, 291-300. [CrossRef]

24. Unsgaard, G.; Ommedal, S.; Muller, T.; Gronningsaeter, A.; Nagelhus Hernes, T.A. Neuronavigation by intraoperative three-dimensional ultrasound: Initial experience during brain tumor resection. Neurosurgery 2002, 50, 804-812. [CrossRef]

25. Tronnier, V.M.; Bonsanto, M.M.; Staubert, A.; Knauth, M.; Kunze, S.; Wirtz, C.R. Comparison of intraoperative MR imaging and 3D-navigated ultrasonography in the detection and resection control of lesions. Neurosurg. Focus 2001, 10, 1-5. [CrossRef] [PubMed]

26. Munkvold, B.K.R.; Jakola, A.S.; Reinertsen, I.; Sagberg, L.M.; Unsgard, G.; Solheim, O. The Diagnostic Properties of Intraoperative Ultrasound in Glioma Surgery and Factors Associated with Gross Total Tumor Resection. World Neurosurg. 2018, 115, e129-e136. [CrossRef]

27. Keles, G.E.; Lamborn, K.R.; Berger, M.S. Coregistration accuracy and detection of brain shift using intraoperative sononavigation during resection of hemispheric tumors. Neurosurgery 2003, 53, 556-562. [CrossRef]

28. Comeau, R.M.; Fenster, A.; Peters, T.M. Intraoperative US in interactive image-guided neurosurgery. Radiographics 1998, 18, 1019-1027. [CrossRef]

29. Letteboer, M.M.; Willems, P.W.; Viergever, M.A.; Niessen, W.J. Brain shift estimation in image-guided neurosurgery using 3-D ultrasound. IEEE Trans. Biomed. Eng. 2005, 52, 268-276. [CrossRef]

30. Chacko, A.G.; Kumar, N.K.; Chacko, G.; Athyal, R.; Rajshekhar, V. Intraoperative ultrasound in determining the extent of resection of parenchymal brain tumours-a comparative study with computed tomography and histopathology. Acta Neurochir. 2003, 145, 743-748. [CrossRef] [PubMed] 
31. Gerganov, V.M.; Samii, A.; Akbarian, A.; Stieglitz, L.; Samii, M.; Fahlbusch, R. Reliability of intraoperative high-resolution 2D ultrasound as an alternative to high-field strength MR imaging for tumor resection control: A prospective comparative study. J. Neurosurg. 2009, 111, 512-519. [CrossRef] [PubMed]

32. Gerganov, V.M.; Samii, A.; Giordano, M.; Samii, M.; Fahlbusch, R. Two-dimensional high-end ultrasound imaging compared to intraoperative MRI during resection of low-grade gliomas. J. Clin. Neurosci. 2011, 18, 669-673. [CrossRef] [PubMed]

33. Rygh, O.M.; Selbekk, T.; Torp, S.H.; Lydersen, S.; Hernes, T.A.; Unsgaard, G. Comparison of navigated 3D ultrasound findings with histopathology in subsequent phases of glioblastoma resection. Acta Neurochir. 2008, 150, 1033-1041. [CrossRef]

34. Unsgaard, G.; Selbekk, T.; Brostrup Muller, T.; Ommedal, S.; Torp, S.H.; Myhr, G.; Bang, J.; Nagelhus Hernes, T.A. Ability of navigated 3D ultrasound to delineate gliomas and metastases—comparison of image interpretations with histopathology. Acta Neurochir. 2005, 147, 1259-1269. [CrossRef] [PubMed]

35. Carl, B.; Bopp, M.; Sass, B.; Nimsky, C. Intraoperative computed tomography as reliable navigation registration device in 200 cranial procedures. Acta Neurochir. 2018, 160, 1681-1689. [CrossRef]

36. Dice, L.R. Measures of the Amount of Ecologic Association Between Species. Ecology 1945, 26, $297-302$. [CrossRef]

37. Zou, K.H.; Warfield, S.K.; Bharatha, A.; Tempany, C.M.; Kaus, M.R.; Haker, S.J.; Wells, W.M., III; Jolesz, F.A.; Kikinis, R. Statistical validation of image segmentation quality based on a spatial overlap index. Acad. Radiol. 2004, 11, 178-189. [CrossRef]

38. Nitsch, J.; Klein, J.; Dammann, P.; Wrede, K.; Gembruch, O.; Moltz, J.H.; Meine, H.; Sure, U.; Kikinis, R.; Miller, D. Automatic and efficient MRI-US segmentations for improving intraoperative image fusion in image-guided neurosurgery. Neuroimage Clin. 2019, 22, 101766. [CrossRef]

39. Huttenlocher, D.P.; Klanderman, G.A.; Rucklidge, W.J. Comparing Images Using the Hausdorff Distance. IEEE Trans. Pattern Anal. Mach. Intell. 1993, 15, 850-863. [CrossRef]

40. Flusser, J.; Suk, T. A moment-based approach to registration of images with affine geometric distortion. IEEE Trans. Geosci. Remote Sens. 1994, 32, 382-387. [CrossRef]

41. Paul, K.; Graessl, A.; Rieger, J.; Lysiak, D.; Huelnhagen, T.; Winter, L.; Heidemann, R.; Lindner, T.; Hadlich, S.; Zimpfer, A.; et al. Diffusion-sensitized ophthalmic magnetic resonance imaging free of geometric distortion at 3.0 and 7.0 T: A feasibility study in healthy subjects and patients with intraocular masses. Investig. Radiol. 2015, 50, 309-321. [CrossRef]

42. Koivukangas, J.; Louhisalmi, Y.; Alakuijala, J.; Oikarinen, J. Ultrasound-controlled neuronavigator-guided brain surgery. J. Neurosurg. 1993, 79, 36-42. [CrossRef]

43. Hata, N.; Dohi, T.; Iseki, H.; Takakura, K. Development of a frameless and armless stereotactic neuronavigation system with ultrasonographic registration. Neurosurgery 1997, 41, 608-613. [CrossRef]

44. Hirschberg, H.; Unsgaard, G. Incorporation of ultrasonic imaging in an optically coupled frameless stereotactic system. Acta Neurochir Suppl. 1997, 68, 75-80. [CrossRef] [PubMed]

45. Prada, F.; del Bene, M.; Mattei, L.; Lodigiani, L.; DeBeni, S.; Kolev, V.; Vetrano, I.; Solbiati, L.; Sakas, G.; DiMeco, F. Preoperative magnetic resonance and intraoperative ultrasound fusion imaging for real-time neuronavigation in brain tumor surgery. Ultraschall Med. 2015, 36, 174-186. [CrossRef]

46. Lunn, K.E.; Paulsen, K.D.; Roberts, D.W.; Kennedy, F.E.; Hartov, A.; West, J.D. Displacement estimation with co-registered ultrasound for image guided neurosurgery: A quantitative in vivo porcine study. IEEE Trans. Med. Imaging 2003, 22, 1358-1368. [CrossRef]

47. Schneider, R.J.; Perrin, D.P.; Vasilyev, N.V.; Marx, G.R.; Del Nido, P.J.; Howe, R.D. Real-time image-based rigid registration of three-dimensional ultrasound. Med. Image Anal. 2012, 16, 402-414. [CrossRef] [PubMed]

48. Coupe, P.; Hellier, P.; Morandi, X.; Barillot, C. 3D Rigid Registration of Intraoperative Ultrasound and Preoperative MR Brain Images based on Hyperechogenic Structures. Int. J. Biomed. Imaging 2012, 2012, 1-14. [CrossRef]

49. Canalini, L.; Klein, J.; Miller, D.; Kikinis, R. Segmentation-based registration of ultrasound volumes for glioma resection in image-guided neurosurgery. Int. J. Comput. Assist. Radiol. Surg. 2019, 14, 1697-1713. [CrossRef] 
50. Rackerseder, J.; Göbl, R.; Navab, N.; Hennersperger, C. Fully Automatic Segmentation of 3D Brain Ultrasound: Learning from Coarse Annotations. arXiv 2019, arXiv:1904.08655.

51. Risholm, P.; Pieper, S.; Samset, E.; Wells, W.M., III. Summarizing and visualizing uncertainty in non-rigid registration. Med Image Comput Comput Assist Interv. 2010, 13 Pt 2, 554-561, PMCID:PMC2976974. [CrossRef] [PubMed]

Publisher's Note: MDPI stays neutral with regard to jurisdictional claims in published maps and institutional affiliations.

(C) 2020 by the authors. Licensee MDPI, Basel, Switzerland. This article is an open access article distributed under the terms and conditions of the Creative Commons Attribution (CC BY) license (http://creativecommons.org/licenses/by/4.0/). 